\title{
Oxygen Uptake Kinetics During and After Exercise are Useful Markers of Coronary Artery Disease in Patients With Exercise Electrocardiography Suggesting Myocardial Ischemia
}

\author{
Akihiko Tajima, BS*,**; Haruki Itoh, MD ${ }^{\dagger}$; Naohiko Osada, MD ${ }^{\dagger}$; Kazuto Omiya, MD ${ }^{\dagger}$; \\ Tomoko Maeda, $\mathrm{MT}^{\dagger}$; Nobuyuki Ohkoshi, BS*; Tokuhiro Kawara, MD**; \\ Tadanori Aizawa, MD*; Karlman Wasserman, MD*
}

\begin{abstract}
Background: The aim of the current study was to determine if the slowed exercise oxygen uptake $\left(\dot{\mathrm{V}} \mathrm{O}_{2}\right)$ kinetics, which is developed by myocardial ischemia, would be accompanied by delayed recovery $\mathrm{V}_{2}$ kinetics in patients with coronary artery disease (CAD).

Methods and Results: Thirty-seven patients with significant ST depression during treadmill exercise underwent cardiopulmonary exercise testing with cycle ergometer. Measurements performed are the ratios of change in increase in oxygen $\left(\mathrm{O}_{2}\right)$ uptake relative to increase in work rate $\left(\Delta \dot{\mathrm{V}} \mathrm{O}_{2} / \Delta \mathrm{WR}\right)$ across anaerobic threshold $(\mathrm{AT})$ and $1 \mathrm{~mm}$ ST depression point (ST-dep), the time constants of $\dot{\mathrm{V}} \mathrm{O}_{2}$ during recovery $\left(\mathrm{T}_{1} / 2 \dot{\mathrm{V}}_{2}\right)$, stress radio-isotope scintigraphy and coronary angiography. Patients were divided into CAD positive (CAD+) and CAD negative $(\mathrm{CAD}-)$ groups, based on coronary angiography. In CAD $+\Delta \dot{\mathrm{VO}}_{2} / \Delta \mathrm{WR}$ decreased above AT and ST-dep, in contrast to CAD- patients. The $\mathrm{T}_{1 / 2} \mathrm{~V}_{2}$ in $\mathrm{CAD}+(103.1 \pm 13.0 \mathrm{~s})$ was greater than that of CAD- $(76.5 \pm 8.7 \mathrm{~s})$ and showed negative correlations to the ratios of $\Delta \dot{\mathrm{V}}_{2} / \Delta \mathrm{WR}$ across AT and ST-dep. These parameters improved in the patients who underwent coronary bypass surgery.

Conclusions: Exercise and recovery $\dot{\mathrm{V}}_{2}$ kinetics were slowed when myocardial ischemia was provoked by exercise. Measurement of exercise and recovery $\dot{\mathrm{V}}_{2}$ kinetics improve the accuracy of the exercise electrocardiogram diagnosis of CAD. (Circ J 2009; 73: 1864-1870)
\end{abstract}

Key Words: Coronary artery disease; Exercise recovery; Oxygen uptake kinetics; $\Delta \dot{\mathrm{V}} \mathrm{O}_{2} / \Delta \mathrm{WR} ; \mathrm{T} 1 / 2 \dot{\mathrm{V}} \mathrm{O}_{2}$

$\mathbf{E}$ xercise electrocardiogram (ECG) is widely used to diagnose and evaluate the severity of patients with coronary artery disease (CAD). However, ischemia detected from the change in the ST segment of the ECG during exercise, is said to be not highly sensitive or specific. A meta-analysis on sensitivity and specificity found $68 \pm 16 \%$ in sensitivity and $77 \pm 17 \%$ in specificity. ${ }^{1}$ For this reason, nuclear medicine stress test ${ }^{2}$ or stress echocardiography by exercise or dobutamine ${ }^{3}$ are used in combination in daily clinical practice. The present study is designed to increase the sensitivity and specificity for detection of myocardial ischemia by non-invasive cardiopulmonary exercise testing (CPET) in which changes in gas exchange occur consequent to exercise-induced myocardial dyskinesis, which accompanies myocardial ischemia.

\section{Editorial p 1795}

Recent reports have shown the usefulness of CPET for detecting myocardial ischemia in CAD patients. ${ }^{4-6} \mathrm{We}^{4}$ and others ${ }^{5,6}$ found that oxygen uptake $\left(\mathrm{V}_{2}\right)$ failed to continue to increase linearly with increasing work rate above the anaerobic threshold (AT) or ischemic threshold during an increasing work rate CPET in CAD patients. When the left ventricular wall becomes hypokinetic, akinetic or even dyskinetic secondary to ischemia, the decreased stroke volume prevents oxygen $\left(\mathrm{O}_{2}\right)$ transport to increase at a rate sufficient to supply the muscles with the $\mathrm{O}_{2}$ needed to regenerate the high energy phosphate (adenosine triphosphate (ATP)) needed by the skeletal muscles to sustain muscle contraction, aerobically. Thus $\dot{\mathrm{V}}_{2}$ fails to increase appropriately for the increasing work rate. Because $\dot{\mathrm{V}}_{2}$ is a product of cardiac output times the arterial-venous $\mathrm{O}_{2}$ difference, its altered kinetics reflects altered cardiac function during exercise.

$\dot{\mathrm{V}} \mathrm{O}_{2}$ kinetics at the beginning of exercise and recovery ${ }^{7}$ reflect abrupt early changes in cardiac output at these 2 functional states, and both are slow to change in patients with congenital heart disease $^{8}$ and heart failure. ${ }^{9} \mathrm{We}$ hypothesized that the work rate above which myocardial

(Received May 7, 2009; revised manuscript received June 3, 2009; accepted June 4, 2009; released online August 7, 2009)

*The Cardiovascular Institute, **Biofunctional Informatics, Graduate School of Health Sciences Tokyo Medical and Dental University, ${ }^{\dagger}$ Department of Cardiology, Sakakibara Heart Institute, Tokyo, $\dagger$ The Division of Cardiology, Department of Internal Medicine, St. Marianna University School of Medicine, Kawasaki, Japan and ‡Respiratory and Critical Care Physiology and Medicine, Harbor-UCLA Medical Center, Harbor, LA, USA

Mailing address: Akihiko Tajima, BS, The Cardiovascular Institute, 7-3-10 Roppongi, Minato-ku, Tokyo 106-003, Japan. E-mail: tajima@ cepp.ne.jp

All rights are reserved to the Japanese Circulation Society. For permissions, please e-mail: cj@j-circ.or.jp 
ischemia occurs would slow the cardiac output response to the increasing work rate and simultaneously increase the $\mathrm{O}_{2}$ deficit. This would be expected to increase the $\mathrm{O}_{2}$ debt in recovery, the latter evidenced by a slowing of recovery $\mathrm{VO}_{2}$ kinetics. To investigate this hypothesis and to determine the sensitivity and specificity of gas exchange measurements to complement traditional tests to detect $\mathrm{CAD}$, we determined the slope ratios of the increase in $\dot{\mathrm{VO}}_{2}$ with respect to the increase in work rate $\left(\Delta \dot{\mathrm{V}} \mathrm{O}_{2} / \Delta \mathrm{WR}\right)$ above compared to below the anaerobic or ischemic threshold in patients with suspected angina and positive ECG changes suggestive of myocardial ischemia. Additionally, the $\dot{\mathrm{V}} \mathrm{O}_{2}$ kinetics during recovery from exercise, as evidence of an increased $\mathrm{O}_{2}$ debt, was compared in CAD positive (+) and negative (-) patients. Thus a progressively increasing work rate test, in which gas exchange was measured, was used to provide evidence of impaired cardiac function at specific exercise levels in patients with suspected CAD.

\section{Methods}

\section{Patients}

Forty-two consecutive patients (average age of $62.9 \pm 9.1$ ranging 38-77 years including 37 males and 5 females) with suspected effort-induced chest pain on exertion, and who exhibited significant ST depression (more than $1 \mathrm{~mm}$ at $60 \mathrm{~ms}$ after $\mathrm{J}$ point for the horizontal ST depression and at $\mathrm{J}$ point for the down-sloping depression) ${ }^{10}$ in a treadmill exercise tolerance test (Bruce protocol) were entered into the study. Each patient underwent a CPET followed by exercise stress radio-isotope (RI) scintigraphy test and coronary angiography (CAG) within 2 weeks. Patients with previous myocardial infarction, left ventricular hypertrophy, dilated cardiomyopathy, valvular heart disease, anemia, and lung diseases (eg, obstructive or restrictive) were excluded. This study was approved by the ethical committee of The Cardiovascular Institute and was conducted according to the guidelines of the Declaration of Helsinki.

\section{Cardiopulmonary Exercise Test}

A symptom-limited CPET was performed on all patients, using an upright cycle ergometer (Corival 400; Lode BV; Groningen, The Netherlands). After a 4-min rest on the ergometer, exercise began with a 4-min warm-up at $0 \mathrm{~W}$, $50 \mathrm{rpm}$, followed by $1-\mathrm{W}$ incremental loading every $6 \mathrm{~s}$. The ECG and heart rate (HR) were monitored throughout the test and recorded every $30 \mathrm{~s}$ by 12 -lead exercise ECG (Stress System ML-4500; Fukuda Denshi Co Ltd; Tokyo, Japan). We determined the point of $1 \mathrm{~mm}$ ST depression (ST-dep) by the ST level trendgram. Cuff blood pressure was also measured every minute with an automatic indirect manometer (Stress Test Blood Pressure Monitor STBP-780; Nippon Colin Co Ltd, Aichi, Japan).

We measured the $\dot{\mathrm{V}} \mathrm{O}_{2}, \mathrm{CO}_{2}$ output $\left(\dot{\mathrm{VCO}}_{2}\right)$ and minute ventilation ( $\dot{\mathrm{V} E})$ on breath-by-breath basis using an expired gas analyzer AE-280S (Minato Medical Science Co Ltd, Osaka, Japan). The system was carefully calibrated before each study. The expired gas data obtained were converted into time-series data every $3 \mathrm{~s}$. Then, an 8-point moving average was performed. From the expired gas analysis, the AT was determined by V-slope method. ${ }^{11}$

Peak $\dot{\mathrm{V}}_{2}$ was defined as the average value obtained during the last $30 \mathrm{~s}$ of incremental exercise. We measured $\Delta \dot{\mathrm{V}} \mathrm{O}_{2} / \Delta \mathrm{WR}$ slopes for $2 \mathrm{~min}$ below and above the AT point and calculated the ratio of the above to the below AT slopes (slope ratio across AT). We also measured $\Delta \dot{\mathrm{V}}_{2} / \Delta \mathrm{WR}$ below and above the ST depression of $1 \mathrm{~mm}$ along with the slope ratio between them (slope ratio across ST-dep). $\Delta \dot{\mathrm{V}} \mathrm{O}_{2} / \Delta \mathrm{WR}$ during exercise was calculated by a linear fit of 2 min ( 40 points) below and 2 min above the AT and ischemic threshold.

The half time for $\dot{\mathrm{V}} 2$ to return to pre-exercise baseline ( $\left.\mathrm{T}_{1 / 2}\right)$ after exercise was calculated from the onset of recovery after exercise. This would reflect the size and rate of repayment of the $\mathrm{O}_{2}$ debt. ${ }^{12}$

There were 3 patients who were ECG positive on the treadmill stress test, but did not show significant ST depression in the cardiopulmonary exercise test, by cycle ergometry. They were excluded from the study.

\section{Stress Radioisotope Scintigraphy}

Within 2 weeks after CPET, patients underwent stress RI scintigraphy using a treadmill with the Bruce protocol. From a bull's eye map, an area counting $2 \times$ standard deviation or less in comparison to a database prepared from 50 normal adults in our hospital was measured. The area of reduced ${ }^{201}$ Thallium uptake was calculated as an extent score which reflects an area where myocardial blood flow is decreased.

\section{CAG}

Thirty-nine patients underwent CAG within 2 weeks after CPET. They were classified based on the results of the angiography as CAD+ or CAD - with or without significant stenosis $(\geq 75 \%)$, respectively. ${ }^{13}$ When patients showed normal coronary arteries, the provocation test for vasospasm, using acetylcholine, was performed. Two patients who diagnosed as vasospastic angina were excluded from the analysis. The left ventricular ejection fraction was measured by left ventriculography.

The medications, such as $\mathrm{Ca}$ antagonists, nitrates, and $\beta$-blockers, were all stopped $24 \mathrm{~h}$ before the CPET, RI scintigraphy, and CAG.

CPET was repeated 3-4 months later in 5 patients who had coronary artery bypass graft surgery (CABG) after the $\mathrm{CAG}$. The same measurements were obtained.

\section{Statistical Analysis}

Statistical analysis was performed using SPSS statistical software (SPSS ver.11.0J, SPSS Japan Inc). Unpaired Student's t-tests were used to compare CAD+ or CADgroup means of CPET variables and patients' backgrounds.

\section{Results}

Two patients diagnosed as vasospastic angina were not included in this analysis. In total, therefore, the data from 37 patients were analyzed (33 males and 4 females, $60.6 \pm$ 9.8 years).

\section{Endpoint of Exercise}

Most of all the patients in the CAD- group stopped the exercise test because of leg fatigue or SOB. In contrast, 16 of 18 patients in the CAD+ group stopped the test because of either chest pain or ST depression of more than $2 \mathrm{~mm}$.

\section{AT, Peak $\dot{\mathrm{V}}_{2}$}

Figure 1 shows the typical $\dot{\mathrm{VO}}_{2}$ kinetics and $\mathrm{HR}-\dot{\mathrm{V}} \mathrm{O}_{2}$ curves during incremental exercise. The CAD- patient (case no. 9) showed a linear, non-changing increase in $\mathrm{VO}_{2}$ 
(A) CAD-
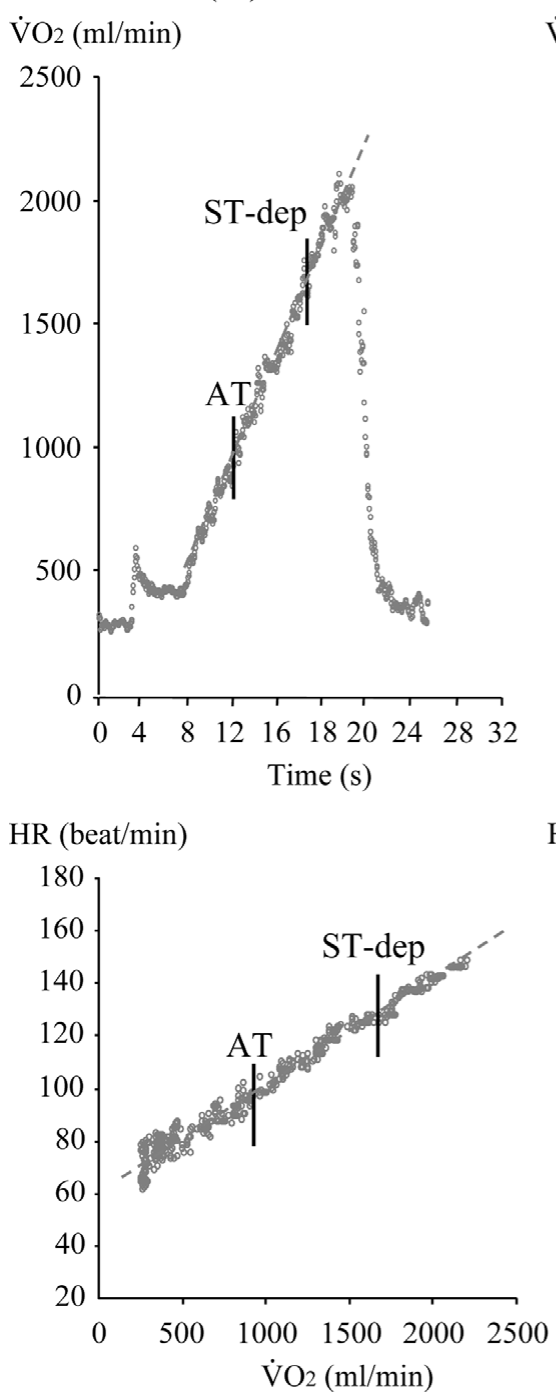

(B) $\mathrm{CAD}+$

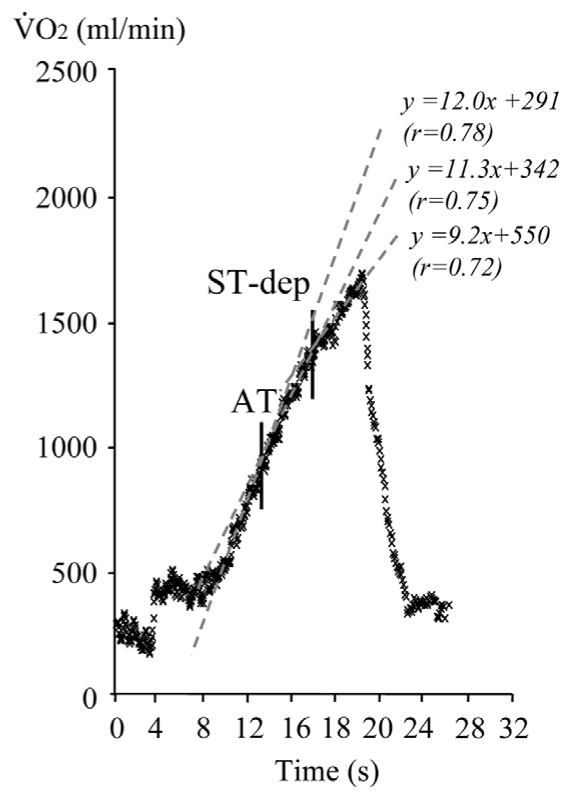

HR (beat/min)

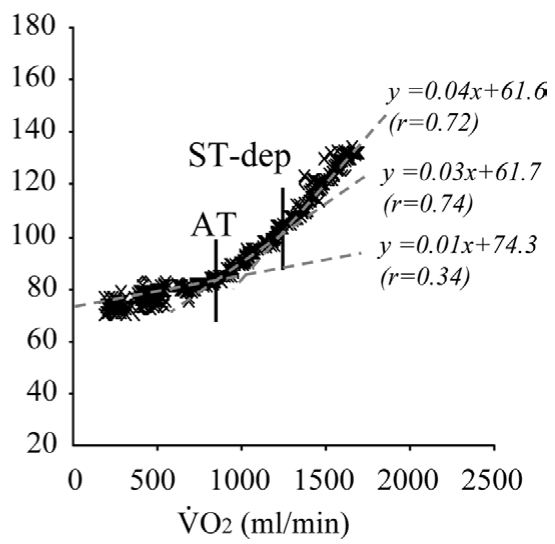

Figure 1. Oxygen uptake $\left(\dot{\mathrm{V}}_{2}\right)$ kinetics (Upper) and heart rate (HR)- $\dot{\mathrm{V}} \mathrm{O}_{2}$ curves during exercise (Lower). In the coronary artery disease (CAD) - patients, $\dot{\mathrm{VO}}_{2}$ increased linear to the work rate below and above anaerobic threshold (AT). However, $\dot{\mathrm{V}} \mathrm{O}_{2}$ increased more slowly above AT than below AT in $\mathrm{CAD}+$ patients. The $\mathrm{HR}-\dot{\mathrm{V}}_{2}$ curves became steeper in CAD+ patient in accordance with exercise intensity while it remained linear in CAD- patient above AT (Lower).

Table 1. Results of Cardiopulmonary Exercise Testing, Radio-Isotope Scintigraphy, and Cardiac Catheterization in Patients With and Without Significant Coronary Stenosis

\begin{tabular}{|c|c|c|c|}
\hline & CAD- group $(n=19)$ & CAD+ group $(n=18)$ & P-values* \\
\hline Age (year) & $56.8 \pm 9.9$ & $64.2 \pm 8.8$ & 0.025 \\
\hline Heart rate at rest (beats/min) & $71.6 \pm 13.1$ & $71.3 \pm 7.6$ & 0.934 \\
\hline Heart rate at peak (beats/min) & $146.5 \pm 18.0$ & $121.1 \pm 15.7$ & $<0.001$ \\
\hline Systolic blood pressure at rest $(\mathrm{mmHg})$ & $141.1 \pm 19.8$ & $142.6 \pm 22.0$ & 0.834 \\
\hline Systolic blood pressure at peak (mmHg) & $221.4 \pm 17.4$ & $187.2 \pm 28.7$ & $<0.001$ \\
\hline Oxygen uptake at AT $\left(\mathrm{ml} \cdot \mathrm{min}^{-1} \cdot \mathrm{kg}^{-1}\right)$ & $13.0 \pm 2.4$ & $12.1 \pm 1.5$ & 0.261 \\
\hline Oxygen uptake at peak $\left(\mathrm{ml} \cdot \mathrm{min}^{-1} \cdot \mathrm{kg}^{-1}\right)$ & $24.1 \pm 4.3$ & $17.9 \pm 3.3$ & $<0.001$ \\
\hline Peak work rate $(\mathrm{W})$ & $122.3 \pm 26.0$ & $82.8 \pm 20.2$ & $<0.001$ \\
\hline $\mathrm{T}_{1 / 2} \dot{\mathrm{VO}} 2(\mathrm{~s})$ & $55.7 \pm 8.8$ & $78.1 \pm 10.9$ & 0.006 \\
\hline Total extent score & $6.2 \pm 11.6$ & $155.8 \pm 151.8$ & $<0.001$ \\
\hline No. of diseased vessels & 0 & $1.9 \pm 0.9$ & \\
\hline Ejection fraction by left ventriculography (\%) & $71.4 \pm 5.1$ & $67.4 \pm 7.6$ & 0.064 \\
\hline
\end{tabular}

*P values by unpaired t-test.

CAD-, patient without significant coronary artery stenosis; $\mathrm{CAD}+$, patient with significant coronary artery stenosis; AT, anaerobic threshold; $\mathrm{T}_{1} / 2 \dot{\mathrm{V}}_{2}$, half time recovery of $\dot{\mathrm{V}}_{2}$ after exercise.

relative to work rate below and above AT. The CAD+ patient (case no. 28) demonstrated same pattern of $\dot{\mathrm{VO}}_{2}$ as CAD- patient below AT. However, the pattern showed a reduced rate of $\dot{\mathrm{V}}_{2}$ increase relative to work rate above AT and ST-dep. Also the CAD+ patient showed a non-linear steepening HR- $\dot{\mathrm{V}}_{2}$ curve, in contrast to the linear $\mathrm{HR}-\dot{\mathrm{V}}_{2}$ curve typical of CAD- patient during increasing work rate exercise (Figure 1 Lower).

AT values averaged $13.0 \pm 2.4$ and $12.1 \pm 1.5 \mathrm{ml} \cdot \mathrm{min}^{-1} \cdot \mathrm{kg}^{-1}$ for the $\mathrm{CAD}-$ and $\mathrm{CAD}+$ groups, respectively, and these 
Slope Ratio Across AT

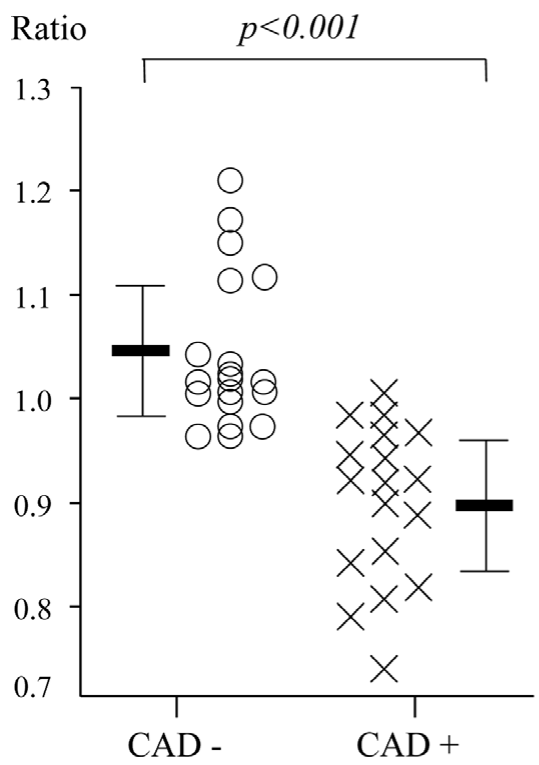

$\mathrm{T}_{1} / 2 \dot{\mathrm{VO}}_{2}$

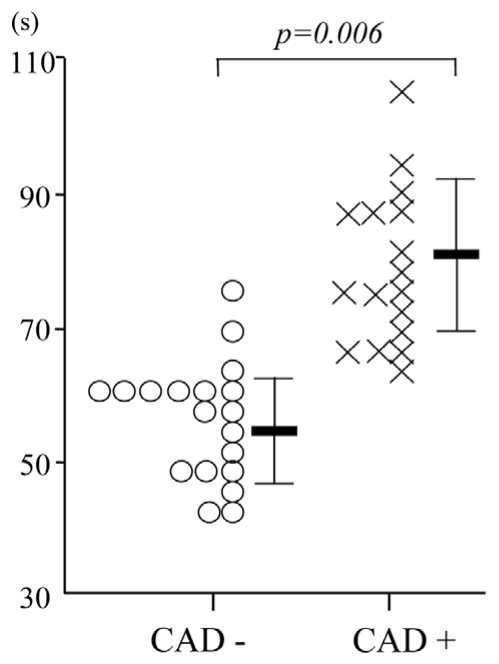

Slope Ratio Across ST-dep

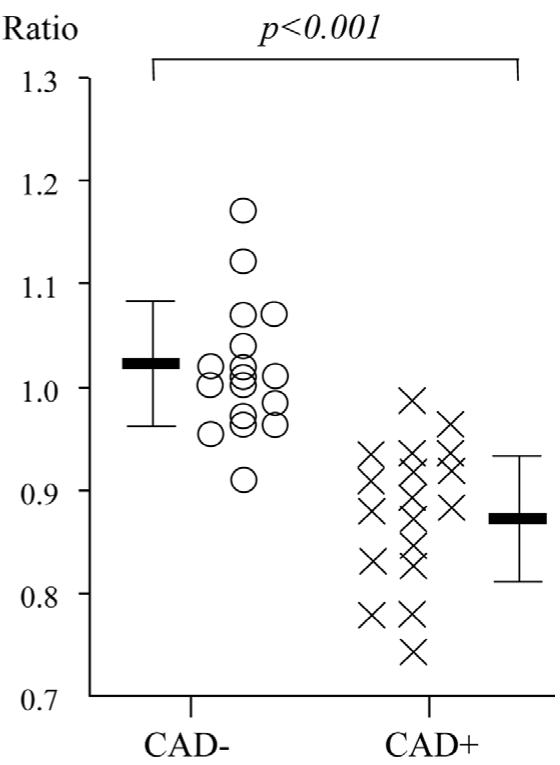

Sensitivity and Specificity Curves of $\mathrm{T}_{1} / 2 \mathrm{~V}_{2}$

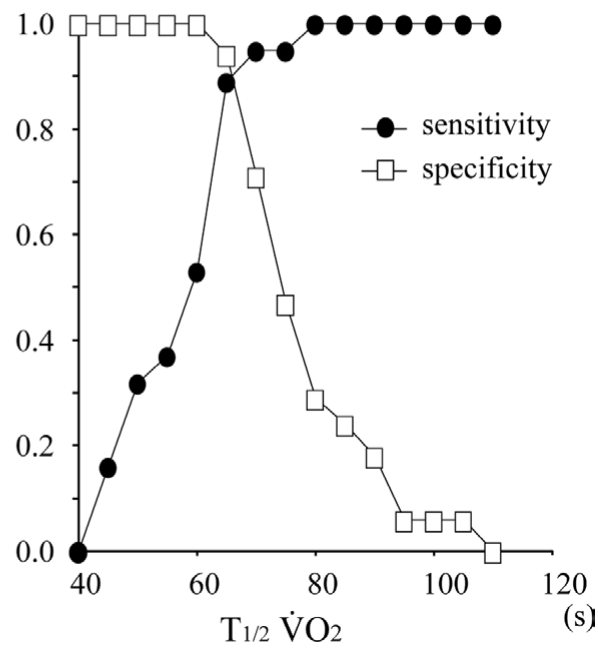

Figure 2. The ratio of $\Delta \dot{\mathrm{V}} \mathrm{O}_{2} / \Delta \mathrm{WR}$ for 2 min below to above anaerobic threshold (AT) (Left) and ratio of $\Delta \dot{\mathrm{V}} \mathrm{O}_{2} / \Delta \mathrm{WR}$ for $2 \mathrm{~min}$ below and above $1 \mathrm{~mm} \mathrm{ST}$ depression point (ST-dep) (Right). There were no statistical difference between the $\Delta \dot{\mathrm{VO}}_{2} / \Delta \mathrm{WR}$ below and above AT in coronary artery disease (CAD) - group, whereas $\Delta \dot{\mathrm{V}} \mathrm{O}_{2} / \Delta \mathrm{WR}$ above AT was significantly lower than that of below AT $(\mathrm{P}<0.001)$ in $\mathrm{CAD}+$ group. Therefore, the slope ratio across AT in $\mathrm{CAD}+$ group was significantly lower than that of CAD- group $(\mathrm{P}<0.001$, Left $)$. The $\Delta \dot{\mathrm{V}} \mathrm{O}_{2} / \Delta \mathrm{WR}$ in the CAD- group for $2 \mathrm{~min}$ below ST-dep was not differrent from that of above ST-dep. In the CAD+ group, $\Delta \dot{\mathrm{V}}_{2} / \Delta \mathrm{WR}$ above ST-dep was significantly lower than that of below ST-dep $(\mathrm{P}<0.001)$. The slope ratio across ST-dep in CAD+ group was significantly lower than that of CAD- group $(\mathrm{P}<0.001$, Right $)$.

Figure 3. Half time of recovery of oxygen uptake $\left(\mathrm{T}_{1 / 2} \dot{\mathrm{V}}_{2}\right)$ in patients without (coronary artery disease (CAD)-) and with $(\mathrm{CAD}+)$ coronary artery stenosis (Left). Sensitivity and specificity curves of the $\mathrm{T}_{1 / 2}$ $\dot{\mathrm{V}}_{2}$ for $\mathrm{CAD}$ (Right). The $\dot{\mathrm{V}} \mathrm{O}_{2}$ kinetics after exercise was slower in the CAD+ group than that in the CAD- group. When we used $65 \mathrm{~s}$ as a cut-off value for CAD+ in $\mathrm{T}_{1 / 2}$ $\dot{\mathrm{V}} \mathrm{O}_{2}$, sensitivity was $89.4 \%$ and specificity was $94.4 \%$.

values were not significantly different (Table 1). Peak $\dot{\mathrm{V}}{ }_{2}$ values averaged $24.1 \pm 4.3$ and $17.9 \pm 3.3 \mathrm{ml} \cdot \mathrm{min}^{-1} \cdot \mathrm{kg}^{-1}$ for the CAD- and CAD+ groups, respectively (Table 1). Peak $\dot{\mathrm{VO}}_{2}$ in the CAD+ group was significantly lower than that of the CAD- group.

\section{$\Delta \dot{\mathbf{V}} \mathrm{O}_{2} / \Delta \mathrm{WR}$ for $2 \mathrm{~min}$ Below and Above AT, and Ratio of $\Delta \dot{\mathbf{V}} \mathrm{O}_{2} / \Delta \mathrm{WR}$ for $2 \mathrm{~min}$ Below to $2 \mathrm{~min}$ Above AT (Slope Ratio Across AT)}

The $\Delta \dot{\mathrm{V}}_{2} / \Delta \mathrm{WR}$ for the CAD- group for 2 min below AT was $10.7 \pm 1.0 \mathrm{ml} \cdot \mathrm{min}^{-1} \cdot \mathrm{W}^{-1}$ and that for $2 \mathrm{~min}$ above AT was $11.1 \pm 0.9 \mathrm{ml} \cdot \mathrm{min}^{-1} \cdot \mathrm{W}^{-1}$. For the CAD+ group, $\Delta \dot{\mathrm{V}} \mathrm{O}_{2} /$ $\Delta \mathrm{WR}$ was $11.0 \pm 2.0 \mathrm{ml} \cdot \mathrm{min}^{-1} \cdot \mathrm{W}^{-1}$ below $\mathrm{AT}$, and $9.8 \pm$ $1.9 \mathrm{ml} \cdot \mathrm{min}^{-1} \cdot \mathrm{W}^{-1}$ above AT. The $\Delta \dot{\mathrm{V}} \mathrm{O}_{2} / \Delta \mathrm{WR}$ values of the 2 groups were similar below AT, whereas it decreased significantly above AT only in the CAD+ group $(\mathrm{P}<0.001)$. Therefore, the ratio of $2 \mathrm{~min}$ below to above AT was different in the 2 groups. Figure 2 shows the slope ratio across
AT was significantly lower in the CAD+ than CAD- group $(1.03 \pm 0.07$ vs $0.89 \pm 0.08, P<0.001$, Figure 2 Left).

\section{$\Delta \dot{\mathrm{V}} \mathrm{O}_{2} / \Delta \mathrm{WR}$ for $2 \mathrm{~min}$ Below and Above ST-Dep, and the Slope Ratio Across ST-Dep}

The $\Delta \mathrm{VO}_{2} / \Delta \mathrm{WR}$ for the CAD- group for 2 min below STdep was $11.6 \pm 1.0 \mathrm{ml} \cdot \mathrm{min}^{-1} \cdot \mathrm{W}^{-1}$ and that of for $2 \mathrm{~min}$ above ST-dep was $11.8 \pm 1.2 \mathrm{ml} \cdot \mathrm{min}^{-1} \cdot \mathrm{W}^{-1}$. For the CAD+ group, $\Delta \dot{\mathrm{V}} \mathrm{O}_{2} / \Delta \mathrm{WR}$ was $10.4 \pm 1.8 \mathrm{ml} \cdot \mathrm{min}^{-1} \cdot \mathrm{W}^{-1}$ below ST-dep, and $9.1 \pm 1.7 \mathrm{ml} \cdot \mathrm{min}^{-1} \cdot \mathrm{W}^{-1}$ above ST-dep. There was no difference in $\Delta \dot{V}^{-1} / \Delta \mathrm{WR}$ values between below ST-dep and above ST-dep in the CAD- group, whereas $\Delta \dot{\mathrm{V}}_{2} / \Delta \mathrm{WR}$ above ST-dep was significantly lower than that of below ST-dep in the CAD+ group $(\mathrm{P}<0.001)$. The slope ratio across ST-dep was significantly lower in the CAD+ group than in the CAD- group $(0.88 \pm 0.07$ vs $1.02 \pm 0.06, \mathrm{P}<0.001$, Figure 2 Right). 
Slope Ratio Across AT vs Total Extent Score

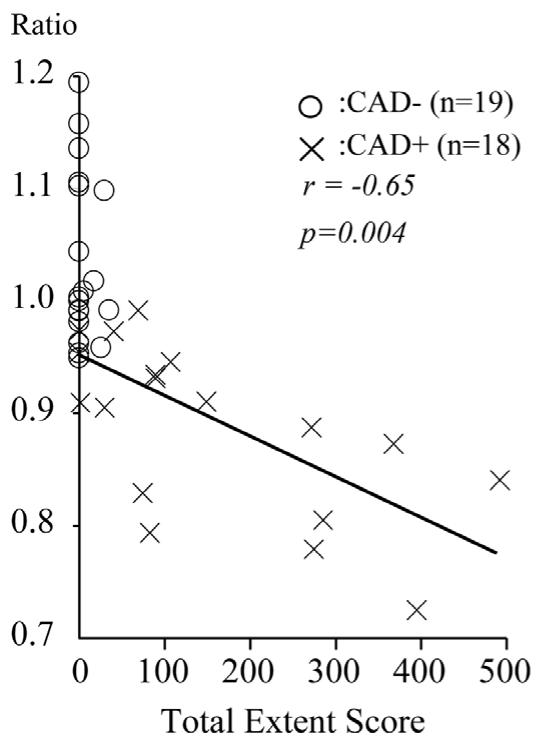

$\mathrm{T}_{1 / 2} \dot{\mathrm{V}}_{2}$ vs Slope Ratio Across AT

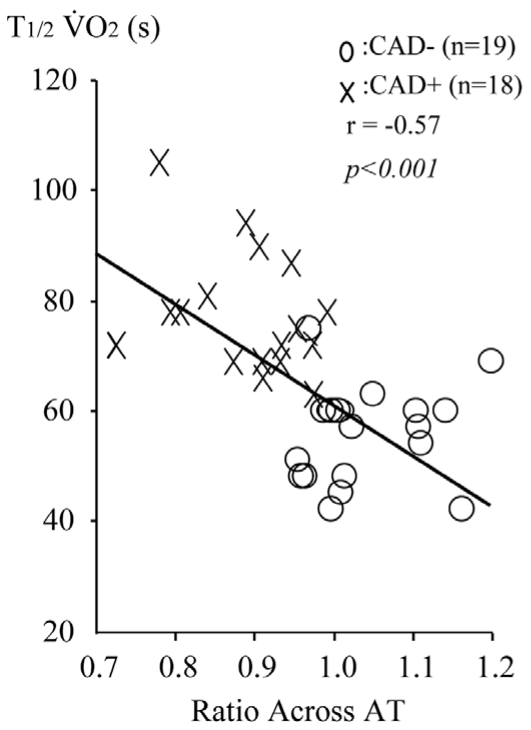

Slope Ratio Across ST-dep vs Total Extent Score

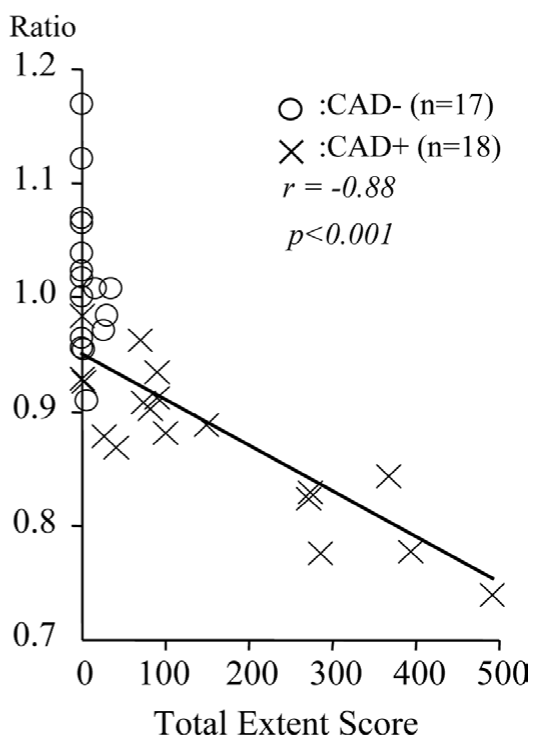

Figure 4. The slope ratios across anaerobic threshold (AT) and ST depression point (ST-dep) in relation to the total extent score. The total extent score calculated from the stress radio-isotope (RI) scintigraphy in $\mathrm{CAD}+$ group showed a significant negative correlation to both of the slope ratio across AT $(r=-0.65, P=0.004)$ and slope ratio across ST-dep $(\mathrm{r}=-0.88, \mathrm{P}<0.001)$.

Figure 5. Half time of recovery of oxygen uptake $\left(\mathrm{T}_{1 / 2} \dot{\mathrm{V}}_{2}\right)$ as related to the slope ratios of $\Delta \dot{\mathrm{V}} \mathrm{O}_{2} / \Delta \mathrm{WR}$ across anaerobic threshold (AT) (Left) and ST depression point (ST-dep) (Right). There were significant correlations between $\mathrm{T}_{1 / 2} \quad \mathrm{VO}_{2}$ and slope ratios across AT or ST-dep.

Table 2. Exercise Parameters Before and After the CABG (n=5)

\begin{tabular}{lccc}
\hline & Pre CABG & Post CABG & P-values* \\
\hline Ejection fraction by left ventriculography $(\%)$ & $65.4 \pm 9.3$ & $68.2 \pm 10.8$ & 0.034 \\
Oxygen uptake at AT $\left(\mathrm{ml} \cdot \mathrm{min}^{-1} \cdot \mathrm{kg}^{-1}\right)$ & $11.9 \pm 1.5$ & $12.4 \pm 2.5$ & 0.057 \\
Oxygen uptake at peak $\left(\mathrm{ml} \cdot \mathrm{min}^{-1} \cdot \mathrm{kg}^{-1}\right)$ & $16.1 \pm 2.6$ & $20.4 \pm 2.0$ & 0.007 \\
Peak work rate $(\mathrm{W})$ & $73.0 \pm 15.9$ & $99.6 \pm 15.9$ & 0.009 \\
Peak O2 pulse $\left(\mathrm{ml} \cdot \mathrm{min}^{-1} \cdot\right.$ beat $\left.^{-1}\right)$ & $7.7 \pm 1.3$ & $9.2 \pm 1.1$ & 0.007 \\
$\mathrm{~T}_{1 / 2} \dot{\mathrm{V} O}$ 2 $(\mathrm{s})$ & $82.4 \pm 8.4$ & $65.4 \pm 7.5$ & 0.018 \\
$\mathrm{Slope}$ above AT & $8.9 \pm 1.5$ & $10.9 \pm 0.5$ & 0.038 \\
$\Delta \dot{\mathrm{V} O} / \Delta$ WR slope ratio across AT & $0.85 \pm 0.07$ & $1.01 \pm 0.05$ & 0.011 \\
$\mathrm{Slope}_{\text {above ST-dep }}$ & $7.7 \pm 1.3$ & $10.6 \pm 0.4$ & 0.009 \\
$\Delta \dot{\mathrm{V} O} / \Delta$ WR slope ratio across ST-dep & $0.86 \pm 0.07$ & $1.02 \pm 0.04$ & 0.023 \\
\hline
\end{tabular}

*P-values by unpaired t-test.

CABG, coronary artery bypass grafting; ST-dep, point of ST depression $(1 \mathrm{~mm})$. Other abbreviations see in Table 1 . 


\section{O2 Kinetics During Recovery Phase}

$\dot{\mathrm{V}} \mathrm{O}_{2}$ kinetics in recovery phase of exercise $\left(\mathrm{T}_{1} / 2 \dot{\mathrm{VO}}_{2}\right)$ was significantly longer in the CAD+ compared to the CADgroup $(78.1 \pm 10.9 \mathrm{~s}$ vs $55.7 \pm 8.8 \mathrm{~s}, \mathrm{P}=0.006$ ) (Figure 3 and Table 1). $\mathrm{T}_{1 / 2} \quad \dot{\mathrm{VO}}_{2}$ showed a significant correlation with both the slope ratio across AT ( $\mathrm{r}=-0.57$ for CAD- group, $\mathrm{P}<0.001)$ and the slope ratio across ST-dep $(\mathrm{r}=-0.65$ for $\mathrm{CAD}+$ group, $\mathrm{P}<0.001$; Figure 5).

\section{Stress RI Scintigraphy}

The total extent score calculated from the stress RI scintigraphy showed a significant positive correlation to $\mathrm{T}_{1 / 2} \dot{\mathrm{V}}_{2}$ $(\mathrm{r}=0.39$ for $\mathrm{CAD}+$ group, $\mathrm{P}=0.011)$. The total extent score also showed a significant correlation with both the slope ratio across $\mathrm{AT}(\mathrm{r}=-0.65$ for $\mathrm{CAD}+$ group, $\mathrm{P}=0.004)$ and the slope ratio across ST-dep ( $\mathrm{r}=-0.88$ for $\mathrm{CAD}+$ group, $\mathrm{P}<0.001$; Figure 4).

\section{Changes in $\mathrm{O}_{2}$ Recovery Kinetics After the $\mathrm{CABG}$}

In 5 patients who underwent CABG (1.9 \pm 1.9 months after

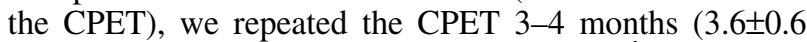
months) after the surgery and measured the $\dot{\mathrm{V}} 2$ kinetics. Because no patients showed significant ST depression after the surgery, we determined $\Delta \dot{\mathrm{V}} \mathrm{O}_{2} / \Delta \mathrm{WR}$ for 2 min below and above ST-dep with the same analysis intervals as before the surgery. The $\Delta \dot{\mathrm{V}} \mathrm{O}_{2} / \Delta \mathrm{WR}$ above AT and previous ST-dep point were improved. The slope ratios across AT and previous ST-dep point were also improved (Table 2) simultaneously with the improvement of $\mathrm{T}_{1 / 2} \dot{\mathrm{VO}}_{2}$ (from $82.4 \pm 8.4$ to $65.4 \pm 7.5)$.

\section{Discussion}

The failure of cardiac output to increase appropriately with work rate is commonly seen in patients with heart failure. This phenomenon reflects the failure for $\dot{\mathrm{V}}_{2}$ (as a result of limited increase in $\mathrm{O}_{2}$ flow) to increase appropriately during exercise to meet the muscle $\mathrm{O}_{2}$ requirement of the work rate. However, in patients with $\mathrm{CAD}$, pumping function of the left ventricle and $\mathrm{O}_{2}$ delivery is not disturbed until the myocardium has an inadequate $\mathrm{O}_{2}$ supply to regenerate ATP. We found that $\Delta \dot{\mathrm{V}} \mathrm{O}_{2} / \Delta \mathrm{WR}$ was decreased when myocardial ischemia developed in CAD+ patients. In this study, we excluded patients who had signs or symptoms of heart failure, and accordingly, there were no differences in AT between the 2 groups.

These findings are in agreement with previous reports ${ }^{4-6}$ and support the concept that the decrease of $\Delta \dot{\mathrm{V}} \mathrm{O}_{2} / \Delta \mathrm{WR}$ above the AT during exercise in CAD is because of the change in cardiac performance caused by myocardial ischemia. AT appears at a lower $\dot{\mathrm{VO}}_{2}$ than ST-dep because myocardial ischemia occurs before the ECG change and ischemia affects the cardiac pumping function. ${ }^{14,15}$

It has been well documented that recovery $\dot{\mathrm{VO}}_{2}$ is prolonged in patients with heart failure. ${ }^{12,16}$ Pavia et al reported that $\mathrm{T}_{1 / 2} \dot{\mathrm{V}} 2$ was prolonged only in the severe heart failure patients and not in the normal individuals and CAD. ${ }^{16}$ But their participants with CAD consisted of myocardial infarction and patients treated with coronary bypass surgery or percutaneous transluminal coronary angioplasty, and there was no evidence of ischemic changes during exercise. In our study, we found that there were significant negative correlations between recovery $\mathrm{T}_{1 / 2}$ for $\dot{\mathrm{V}}_{2}$ and slope ratios across AT and ST-dep (Figure 5). This supports the physiological causality among the impaired pumping function of the heart caused by ischemia and the increased $\mathrm{O}_{2}$ deficit during ischemic exercise. Also there was a significant negative correlation between the slope ratios and the extent score obtained by stress RI scintigraphy, which stands for the area of exercise induced myocardial ischemia.

The abnormal kinetics of $\dot{\mathrm{V}} \mathrm{O}_{2}$ during incremental exercise improved in 5 patients who underwent CABG surgery (Table 2). This supports the physiological relationship between myocardial ischemia and abnormal $\dot{\mathrm{VO}}_{2}$ kinetics.

It is easier to measure the kinetics of $\dot{\mathrm{VO}}_{2}$ in the recovery phase than during exercise because $\Delta \dot{\mathrm{VO}}_{2} / \Delta \mathrm{WR}$ above STdep might not be determined because of the short time of exercise duration. The $\dot{\mathrm{VO}}_{2}$ decay in recovery is not affected by the exercise duration in an increasing work rate test $\mathrm{t}^{12,17}$ and is easily determined when patients perform at least $50 \%$ of maximum exercise. Another advantage for use of T1/2 in recovery as a marker for myocardial ischemia is its sensitivity and specificity. When we employed $65 \mathrm{~s}$ as a cut-off value for CAD+, sensitivity was $89.4 \%$ and specificity was 94.4\% (Figure 3 Rright). The age matched normal value of $\mathrm{T}_{1 / 2} \mathrm{VO}_{2}$ is $56.9 \pm 7.0 \mathrm{~s}$ (50-70 years, $60.2 \pm 5.3$ years).

\section{Study Limitations}

We used the 'significant stenosis in coronary arteries by CAG' as a gold standard for CAD. However, more than $75 \%$ stenosis does not necessarily cause myocardial ischemia during exercise. Therefore we also measured the extent score using RI scintigraphy; however, it indicated the severity of ischemia caused by the maximum exercise, not during exercise.

\section{Conclusions}

We concluded that $\dot{\mathrm{V}} 2$ kinetics was slowed during increasing work rate exercise above the AT and in recovery in patients with regional myocardial ischemia. Presumably the change was consequent to the impaired increase in the cardiac output as work rate increased above the ischemic threshold of the myocardium. Accordingly, the $\dot{\mathrm{V}} \mathrm{O}_{2}$ with the slowed $\dot{\mathrm{V}}_{2}$ kinetics and the magnitude of the slowing reflected the severity of the ischemia. This phenomenon might be useful in differentiating false-positive from truepositive ECG changes during exercise testing for CAD.

\section{Acknowledgment}

The authors thank Dr Takuro Kubozono, Dr Ken Tanaka, Ms Naomi Harada, Ms Reiko Ohara, Ms Kaori Yamaguchi, Mr Osamu Nagayama, Ms Keiko Kohno and Mr Yoshinori Kitabatake for their efforts to perform this study. The authors also thank to Mr Hidetaka Itoh for his statistical assistance.

\section{Disclosure}

No authors have any conflicts of interest.

\section{References}

1. Gianrossi R, Detrano R, Mulvihill D, Lehmann K, Dubach P, Colombo A, et al. Exercise-induced ST depression in the diagnosis of coronary artery disease. Circulation 1989; 80: 87-98.

2. James L, Timothy M, Robert O, Michael H, Raymond J, Robert J, et al. Guidelines for Clinical Use of Cardiac Radionuclide Imaging: A Report of the American Heart Association/American College of Cardiology Task Force on Assessment of Diagnostic and Therapeutic Cardiovascular Procedures (Committee on Radionuclide Imaging), developed in collaboration with the American Society of Nuclear Cardiology. Circulation 1995; 91: 1278-1303.

3. Melvin D, Joseph S, William F, Gerard P, George A, Fredrick Z, et al. ACC/AHA guidelines for the clinical application of echocardiogra- 
phy: A report of the American College of Cardiology/American Heart Association Task Force on Practice Guidelines (Committee on Clinical Application of Echocardiography): Developed in collaboration with the American Society of Echocardiography. Circulation 1997; 95: $1686-1744$

4. Itoh H, Tajima A, Koike A, Osada N, Maeda T, Kato M, et al. Oxygen uptake abnormalities during exercise in coronary artery disease: Cardiopulmonary Exercise Testing and Cardiovascular Health. Armonk, New York: Futura Publishing Co; 2002; 165-172.

5. Belardinelli R, Lacalaprice F, Carle F, Minnucci A, Cianci G, Perna $\mathrm{G}$, et al. Exercise-induced myocardial ischemia detected by cardiopulmonary exercise testing. Eur Heart J 2003; 24: 1304-1313.

6. Bussotti M, Apostolo A, Andreini D, Palermo P, Contini M, Agostoni P. Cardiopulmonary evidence of exercise-induced silent ischemia. Eur J Cardiovasc Prev Rehabil 2006; 13: 249-253.

7. Shimizu N, Koike A, Koyama Y, Kobayashi K, Marumo F, Hiroe M. Kinetics of pulmonary gas exchange during and while recovering from exercise in patients after anterior myocardial infarction. Jpn Circ $J$ 1999; 63: 459-466.

8. Sietsema KE, Daly JA, Wasserman K. Early dynamics of $\mathrm{O}_{2}$ uptake and heart rate as affected by exercise work rate. J Appl Physiol 1989; 67: $2535-2541$

9. Koike A, Yajima T, Adachi H, Shimizu N, Kano H, Sugimoto K, et al. Evaluation of exercise capacity using submaximal exercise at a constant work rate in patients with cardiovascular disease. Circulation 1995; 91: 1719-1724.

10. Gerald FF, Gary JB, Ezra AA, Bernard C, Robert E, Jerome F, et al. Exercise Standards for Testing and Training: A Statement for Health- care Professionals From the American Heart Association. Circulation 2001; 104: 1694-1740.

11. Beaver WL, Wasserman K, Whipp BJ. A new method for detecting anaerobic threshold by gas exchange. J Appl Physiol 1986; 60: $2020-2027$

12. Cohen-Solal A, Laperche T, Morvan D, Geneves M, Caviezel B, Gourgon R. Prolonged kinetics of recovery of oxygen consumption after maximal graded exercise in patients with chronic heart failure. Circulation 1995; 91: 2924-2932.

13. Austen WG, Edwards JE, Frye RL, Gensini GG, Gott VL, Griffith LS, et al. A reporting system on patients evaluated for coronary artery disease: Report of the ad hoc committee for grading of coronary artery disease, Council on Cardiovascular Surgery, American Heart Association. Circulation 1975; 51(4 Suppl): 5-40.

14. Upton MT, Rerych SK, Newman GE, Port S, Cobb ER, Jones RH. Detecting abnormalities in left ventricular function during exercise before angina and ST-segment depression. Circulation 1980; 62: 341-349.

15. Kubozono T, Itoh H, Oikawa K, Tajima A, Maeda T, Aizawa T, et al. Peak $\mathrm{VO}_{2}$ is more potent than B-type natriuretic peptide as a prognostic parameter in cardiac patients. Circ J 2008; 72: 575-581.

16. Pavia L, Myers J, Cesare R. Recovery kinetics of oxygen uptake and heart rate in patients with coronary artery disease and heart failure. Chest 1999; 116: 808-813.

17. Koike A, Nagayama O, Hoshimoto-Iwamoto M, Suzuki T, Tajima A, Uejima $\mathrm{T}$, et al. Clinical significance of cerebral oxygenation during exercise in patients with coronary artery disease. Circ J 2008; 72: $1852-1858$. 